\title{
Educando al buen ciudadano. Las guardias nacionales en la Provincia de Cartagena, Colombia, 1832-1857/
}

\author{
Educating the good citizen. The role of national guard \\ in the Province of Cartagena, Colombia, 1832-1857
}

\author{
Roicer Flórez Bolívar y Sergio Paolo Solano \\ Universidad de Cartagena de Indias, Colombia
}

\begin{abstract}
Este artículo analiza el papel desempeñado por la Guardia Nacional en la Provincia de Cartagena en la formación y educación de los ciudadanos entre 1832 y 1857. Asimismo, se determinan los sectores sociales que integraban esta institución. Se sostiene la idea de que para sus miembros, el servicio de las armas se convirtió en una forma de intervención política más directa, ya que durante ese siglo la ciudadanía se asociaba estrechamente con la participación en las milicias y debido a que la condición de ciudadano activo implicaba el derecho y el deber de pertenecer a ella. De igual forma, la Guardia Nacional se convirtió en un instrumento de sociabilidad y pedagogía política.

Palabras Claves: Artesanos; Guardias nacionales; Ciudadanía; Provincia de Cartagena; Pedagogía.

This article analyzes the role played by the National Guard in the Province of Cartagena in training and education of citizens between 1832 and 1857. Also, determine the social sectors that made up this institution. It supports the idea that members of this Guard, military service became a form of more direct political intervention, because during that century citizenship is closely associated with participation in the militias and because active citizen status implies the right and duty to belong to it. Similarly, the National Guard became an instrument of sociability and political pedagogy.
\end{abstract}

Keywords: Artisan; National Guard; Citizenship; Province of Cartagena; Pedagogy. 


\section{Presentación}

En la década de los noventa del siglo pasado, el tema de la ciudadanía cobró un inusitado interés para los historiadores. Diversas corrientes historiográficas sugirieron novedosos enfoques revisionistas y se enmarcaron dentro de la temática general de revalorar la historiografía política en Latinoamérica. ${ }^{1}$ Lo anterior llevó a que un grupo de historiadores estudiara la forma en que los sectores populares hicieron uso del ideario liberal republicano, en especial del concepto de ciudadanía, para proteger sus intereses y los de sus comunidades. ${ }^{2}$ Otros han investigado el proceso de construcción de la ciudadanía en los diferentes países de América Latina y los problemas que enfrentaron a lo largo del siglo XIX los nuevos Estados para llevar a cabo dicho proceso. ${ }^{3}$

Una rápida mirada a la historiografía sobre el tema muestra que el grueso de las preocupaciones se ha concentrado en el tema de las prácticas del voto, es decir, se ha reorientado el análisis hacia el electorado revalorizando su composición y su papel en la política. Dentro de esta línea revisionista existe un creciente interés en identificar con mayor precisión sus valores y aspiraciones y en determinar hasta qué punto supo sacar ventaja del poder que le confería el voto. ${ }^{4}$

En el caso de Colombia su historiografía no ha sido ajena a estos cambios, lo que se evidencia en el número creciente de estudios que analizan las prácticas electorales durante el siglo XIX. ${ }^{5}$ De igual forma, también se viene explorando la relación entre sectores populares con la ideología liberal y la ciudadanía. ${ }^{6}$ Finalmente, también se ha avanzado en el análisis de las pedagogías republicanas (manuales escolares, catecismos políticos, la prensa, las fiestas y símbolos patrios) como mecanismos que buscaban educar al pueblo en los nuevos valores republicanos y legitimar a los nacientes Estados nacionales. ${ }^{7}$

1 Posada, 2003, p. 70.

2 Annino, 1999, pp. 62-92; Graham, 1999, pp. 345-401; Murilo, 1999, pp. 321-344; GarcíaBryce, 2008, pp. 121-166; Conde, 2009, pp. 101-177; Núñez, 2007, pp. 235-253; Flórez, 2006, pp. $135-152$. pp. 371-404.

3 Guerra, 1999, pp. 33-61; Chiaramonte, 1999, pp. 94-118; Carmagnani y Hernández, 1999,

4 Irurozqui, 1999, pp. 99-117 y 1999b, pp. 295-317; Posada, 1999, pp. 162-180.

5 Bushnell, 1975, p. 125; Deas, 2006, pp. 209-234; González, 1997, pp. 70-95.

6 Saether, 2008, pp. 55-80; Sanders, 2004, pp. 18-57; Sowell, 2006, pp. 143-171; Cruz, 2009, pp. 255-297; Conde, 2009, p. 370 ; Múnera, 1997, pp. 173-215; Lasso, 2007, pp. 68-150.

7 Alarcón, 2000, pp. 25-55 y 2002, pp. 40-55; Conde, 1999, pp. 120-140 y 2000, pp. 56-80. 
Nuestro trabajo se halla inserto dentro de esta última temática. Lo que pretendemos es profundizar en los mecanismos utilizados por los Estados nacionales en la construcción y aprendizaje de la ciudadanía política y uno de los espacios que ha sido objeto escaso de análisis por parte de la historiografía colombiana es el de la relación entre ciudadanía, pedagogía republicana e instituciones militares. Sin duda, al igual que la escuela y los manuales y catecismos políticos, en el siglo XIX las instituciones militares (ejército y guardias nacionales) fueron herramientas utilizadas no sólo en la construcción del ciudadano "ideal" sino en la legitimidad de los Estados nacionales. En ese sentido, en este artículo analizamos el papel desempeñado por la Guardia Nacional en la provincia de Cartagena en la formación y educación de los ciudadanos entre 1832 y 1853 . Asimismo, determinamos los principales sectores sociales que integraban esta institución.

A lo largo del ensayo defendemos las siguientes ideas: 1) La institución de la Guardia Nacional fue utilizada por el Estado colombiano como una herramienta de sociabilidad y pedagogía política, con objeto de ayudar en la construcción y educación del ciudadano "ideal". En ese sentido, coincidimos con otros investigadores ${ }^{8}$ acerca de que en el siglo XIX, además de la presión ejercida por amplios sectores de abajo para gozar de la ciudadanía, ésta también fue una construcción desde arriba, jugando los Estados un papel primordial. 2) Al convertirse la patria en el siglo XIX en el nuevo punto de referencia de toda lealtad, la imagen social de los miembros de la Guardia Nacional se vio reforzada por ser, junto al ejército, las principales fuerzas defensoras de las instituciones democrático-liberales. Esto determinó que el servicio de las armas fuera uno de los mecanismos mediante el cual artesanos, negros y mulatos, en la provincia de Cartagena, accedieran al reconocimiento y la valía social de la comunidad. A través del servicio como guardias nacionales, este grupo social logró crear y mantener un espacio político en la sociedad cartagenera de la primera mitad del siglo XIX. 3) Sin embargo, la Guardia Nacional fue una institución que no logró escapar a las realidades políticas y partidarias de la época. Al estar conformada por ciudadanos activos, con derechos a elegir y ser elegidos y primando en la Nueva Granada una ciudadanía de carácter censitario, donde una buena parte de la población estaba excluida del derecho al voto, los ciudadanos de las armas eran una instancia de poder utilizada por los gobiernos de turno, los partidos políticos y las facciones durante las elecciones.

8 Graham, 1999, pp. 345-401; Murilo, 1999, pp. 321-344; Peralta, 1999, pp.231-252. 


\section{Estado republicano, ciudadanía y guardias nacionales}

Terminadas las guerras de independencia, los nacientes Estados latinoamericanos empezaron el largo y difícil camino de consolidarse como naciones. Guiados por las ideas del progreso y la civilización, las elites de estos países aspiraron a moldear a la sociedad y al individuo en concordancia con la ideología liberal. Para ello, cada una de las Constituciones establecidas en Latinoamérica determinó que el ciudadano sería la figura central de la sociedad y que gozaría de libertades individuales que le permitirían su libre desarrollo y alcanzar la felicidad. No obstante, debían cumplir con unos deberes. El más importante era la lealtad que debían guardar hacia la patria y que se expresaba en la voluntad de sacrificar sus vidas en defensa de las instituciones republicanas y el mantenimiento de la legitimidad estatal.

La Nueva Granada no fue ajena a este ideal. Las constituciones políticas de la primera mitad del siglo XIX eran enfáticas en determinar que el deber sagrado de los ciudadanos era la defensa de la patria. Por ejemplo, la Constitución de la República de Cundinamarca de 1812 establecía una relación directa entre gozar de los derechos de ciudadanía y ser soldado. En su artículo 30 manifestaba: "todo ciudadano desde la edad de quince años hasta la de cuarenta y cinco, para gozar de los derechos de tal, deberá inscribirse en la lista militar de la Nación" y la Constitución de la República de Colombia de 1830 también establecía que entre los deberes de los ciudadanos estaba "servir y defender a la patria, haciendo el sacrificio de su vida si fuere necesario". 9

En ese sentido, en palabras de Flavia Macías, el patriotismo expresaba el sentido de lealtad en clave militar, de modo que el servicio de las armas a la nación era entendido como un deber y un compromiso moral de los individuos con el Estado. Este pensamiento delineaba la imagen del "ciudadano armado" materializada en el individuo integrante de la Guardia Nacional, cuya función esencial era la de armarse en defensa de su patria y de su Constitución, actuando como garante del orden interno. En última instancia, el objetivo perseguido por el Estado era incentivar en los individuos las conductas y los deberes cívicos, en especial el patriotismo y la lealtad nacional. Con estas prácticas se buscaba proyectar en la sociedad la imagen ideal del ciudadano "patriota" y "virtuoso". ${ }^{10}$

9 Pombo y Guerra, 1951, pp. 61 y 156.

10 Macías, 2003, p. 140. 
En el caso de la Nueva Granada, en 1832 las elites que agenciaron la remodelación de la República se percataron de la necesidad de tener un cuerpo militar adepto a las directrices constitucionales y que tuviese una orientación no deliberativa. Además, un ejército permanente reducido le garantizaba al Estado un cuerpo castrense de fácil manejo y si éste en algún momento se mostraba beligerante, los cuerpos provinciales (guardias nacionales) podían ser, en un momento dado, una fuerza capaz de enfrentarse a sus compañeros díscolos. ${ }^{11}$ La milicia constituía el verdadero sistema republicano de defensa del pueblo. El guardia nacional era el ciudadano activo defensor de las virtudes cívicas, como lo puso de manifiesto el presidente de la República en 1840: "La guardia nacional ha correspondido en todas partes al llamamiento del gobierno, y sin distinguirse de los veteranos ha hecho como ellos el servicio militar, y vencidos como ellos en diversas ocasiones. Repetidas veces ha reclamado el gobierno una ley que la organice convenientemente, para que con ella se ponga la República en estado de defender sus derechos y sostener sus libertades". ${ }^{12}$ Pero ¿cómo se hallaban estructuradas las guardias nacionales?, ¿Cuáles eran sus funciones?

\section{Estructura y funciones de la Guardia Nacional}

Las guardias nacionales tuvieron como modelo a la Guardia Nacional francesa, creada en 1789 en vísperas de la toma de La Bastilla. El objeto de este cuerpo francés era poner la defensa del país en manos de los propietarios, de los ciudadanos activos, como los definió más tarde la Constitución de 1791. Esta Carta Magna, por otra parte, identificaba al ciudadano como el guardia nacional. Solo podía votar quien estuviese en la Guardia. ${ }^{13}$ Según José Murilo de Carvalho, esta institución militar fue copiada en la mayoría de los nacientes países latinoamericanos durante la primera mitad del siglo XIX. En Brasil, inicialmente los fines eran parecidos a los de la francesa. Creada en 1831, en medio de grandes agitaciones políticas, la guardia debía servir como protección contra la anarquía que se había adueñado del ejército y contra las revueltas populares que estallaban una tras otra en distin-

11 Prado, 2008, p. 230.

12 Biblioteca Bartolomé Calvo (en adelante BBC), Semanario de la Provincia de Cartagena (en adelante SPC), Cartagena, 22 de junio de 1840.

13 Murilo, 1999, p. 334. 
tas capitales..$^{14}$ Además de en Brasil, se organizaron en México, Argentina, Venezuela, Perú, Bolivia, la Nueva Granada y otros. ${ }^{15}$

En la Nueva Granada, la Guardia Nacional fue organizada durante la guerra de independencia como consecuencia del bajo número de milicianos existentes. Por ejemplo, en 1799 apenas llegaba a 7.740 hombres para una población de casi dos millones. ${ }^{16}$ José María Espinosa, autor de la época, resalta que en 1812, "restablecida al fin la calma y organizado el gobierno en Cundinamarca, comenzaron a formarse los cuerpos militares y yo, engolosinado ya con los alborotos, y con la feliz e incruenta campaña del 20 de Julio, tomé servicio en el Batallón de guardias nacionales, del cual me hicieron alférez abanderado" ${ }^{17}$ Esta institución sería ratificada en la Nueva Granada por cada una de las constituciones de la primera mitad del siglo XIX hasta el año de 1857, cuando fue reemplazada por las milicias de los Estados Soberanos en los que se organizó el país hasta $1886 .{ }^{18}$

Las guardias nacionales eran cuerpos territoriales de defensa no profesionales encargados de luchar contra las agresiones exteriores, proteger la seguridad de la República, sostener su independencia, velar por la conservación de las libertades y mantener el orden público. Ahora bien, nada ilustra mejor el poder de las autonomías regionales en la Nueva Granada como la Guardia Nacional. Si bien estaba conformada por ciudadanos neogranadinos, éstos tenían que defender solamente las fronteras de su Provincia. No era permitido por la ley movilizar a los miembros de la Guardia Nacional a otra Provincia cuando no se encontraba en caso de conmoción interior. Verbigracia, en 1839 el general Joaquín Posada Gutiérrez solicitó la movilización de cincuenta hombres de la Guardia Nacional de la provincia de Cartagena para ser llevados a someter un levantamiento armado en la de Santa Marta. La razón que se adujo para no aprobar esta solicitud fue que "el artículo 69 de la ley orgánica de provincia, señala que de ninguna manera se sacará del cantón para provincia diferente a la guardia nacional y menos cuando no hay tal conmoción interior; hacer lo contrario es quebrantar la ley". ${ }^{19}$ En ese sentido, este cuerpo que estudiamos era el reflejo del sutil equilibrio entre las ciudades, localidades, etc., y el poder

14 Ibidem, p. 335.

15 Escalante, 1993, p. 262 p; Macías, 2003, pp. 137-151; Hébrard, 2002, pp. 429-462; Peralta, 1999, pp. 231-254; Irurozqui, 2006, pp. 35-46; Uribe, 2004, pp. 75-92.

16 Thibaud, 2003, p. 58.

17 Espinosa, 1971, p. 37.

18 Pombo y Guerra, 1951, p. 18.

19 Archivo Histórico de Cartagena (en adelante AHC), Cartagena, 5 de enero de 1839. 
central, mostrando el poder local del monopolio del reclutamiento y el control político de la población.

En cada Provincia estaban a las órdenes de su respectivo gobernador, quien las llamaría al servicio en los casos que determinaba la ley, o cuando el Poder Ejecutivo lo ordenara con acuerdo del Congreso o del Consejo de Estado en receso de aquel; o sin estos requisitos, para actuar dentro de la Provincia, en caso de conmoción súbita o de invasión exterior repentina. Por otro lado, cuando los individuos de la Guardia Nacional estaban en servicio, quedaban sujetos a las ordenanzas militares, lo que significaba que si estaban en campaña eran juzgados por las ordenanzas del ejército; pero estando de guarnición solamente lo serían en los delitos puramente militar. Se entendía que se hallaban en servicio cuando estaban acuartelados y debían ser pagados por el Estado, aun cuando algunos la sirvieran gratuitamente. ${ }^{20}$

Para ingresar en ellas se necesitaba ser granadino y vecino de la Provincia. Mientras que en la auxiliar debían alistarse los granadinos que tuvieran entre diez y ocho y cuarenta años de edad y los que no habiendo cumplido los cincuenta estuviesen excluidos de la local, en esta última lo hacían todos los que tuvieran desde diez y seis hasta diez y ocho y cuarenta hasta cincuenta. Estaban exentos del alistamiento y del servicio en ambas milicias los notoriamente inútiles, los ordenados in sacris, los oficiales retirados de cuartel indefinidos del ejército o la marina, los religiosos profesos y los novicios. También lo estaban sólo del servicio en las faenas ordinarias, pero no del alistamiento, los rectores, los catedráticos de las universidades y colegios y sus sustitutos, los directores de casas de estudios y los maestros de escuelas públicas. ${ }^{21}$

La Guardia Nacional auxiliar era una milicia de reserva. Cooperaba con el ejército permanente en los casos en que la ley lo señalaba. Ante una guerra civil o por la invasión de un país extranjero debía ser movilizada para defender las fronteras de la Provincia y de la Nación. Por tanto, se esperaba que sus miembros estuvieran sujetos a una disciplina, que se traducía en el estricto cumplimiento de los ejercicios programados por la línea de mando. La Guardia Local era todo lo contrario y entre las funciones que debía cumplir en tiempos de paz se encontraban la de prestar eficaz auxilio a las autoridades del distrito parroquial respectivo para obligar al cumplimiento de las leyes y ordenanzas o acuerdos de las corporaciones municipales o para

20 Pombo, y Guerra, 1951, p. 220.

21 BBC, SPC, Cartagena, 2 de abril de 1843 y 7 de octubre de 1849. 
hacer cumplir las órdenes legales de las autoridades políticas o judiciales, siempre que para la obediencia a tales actos y resoluciones no hubiese bastado el auxilio ordinario de los agentes de la policía. De igual forma, montar guardia en la cárcel del distrito para custodiar los reos sentenciados a último suplicio, o para custodiar también a los famosos criminales que podían fugarse por falta de seguridad en la cárcel o en las prisiones, siempre que para estos objetos no bastaran los empleados estipulados o que se establecieran en los distritos parroquiales; pero nunca sería obligada a la ejecución de los reos. El servicio de la Guardia se hacía por turno riguroso y ningún individuo que lo hubiera prestado durante dos días seguidos podía ser obligado a volver a servir hasta que no hubieran turnado todos los demás que se hallaban en el distrito parroquial y con capacidad de servir. ${ }^{22}$

En el caso concreto de la Provincia de Cartagena, cada uno de sus cantones debía contar con Guardia Nacional tanto local como auxiliar. Por tanto, tenían que organizarse en Cartagena, Barranquilla, Corozal, Chinú, Lorica, Mahates, Sabanalarga, Soledad y San Andrés. El total de hombres con el que contaba cada uno de estos cuerpos lo determinaba el número de habitantes que poseía cada cantón. Para su organización, los jefes políticos y los alcaldes parroquiales abrían dos registros con el encabezamiento respectivo a cada uno de Guardia Nacional auxiliar y Guardia Nacional local, en los cuales inscribirían los nombres y apellidos de los individuos que se presentaban, con indicación de su edad y el lugar de su residencia, colocándolos en el registro al que correspondían por la edad. Todo individuo que, pasados los veinte días prevenidos en el artículo $1 .^{\circ}$, no se hubiera inscrito en los registros de la Guardia Nacional, sería castigado con la multa de ocho a diez y seis reales, y si no pudiese pagar dicha multa, se le destinaría a trabajos públicos por tres días o enviado al ejército permanente. ${ }^{23}$ Esto último mostraba las diferencias sociales de los miembros de ambas instituciones. Mientras el ejército era visto como una institución de castigo para los vagos o criminales, la Guardia Nacional estaba pensada para los ciudadanos trabajadores, industriosos, educados y con derechos políticos. ${ }^{24}$

Esta Guardia se hallaba estructurada en batallones de artillería e infantería y cada uno de ellos se dividía en compañías dependiendo del número de milicianos con que contaban, respectivamente. Esas compañías debían estar integradas por un sargento $1 .^{\circ}$ y cuatro $2 .^{\circ}$, dos tambores o dos corne-

22 Ibidem, Cartagena, 21 de octubre de 1849.

23 Ibidem, Cartagena, 7 de octubre de 1847.

24 Escalante, 1993, pp. 168-170. 
tas, diez cabos $1 .^{\circ}$ y doce $2 .^{\circ}$ y noventa y un soldados. El sargento $1 .^{\circ}$ y un cabo de la clase de $1 .^{\circ}$ o $2 .^{\circ}$ de cada compañía serían plazas veteranas que se designaban de las que existían empleadas en ese momento en los cuerpos de la Guardia Nacional o de los cuerpos de la guarnición de la Provincia.

En 1847, el estado general de las fuerzas que pertenecían a la Guardia Nacional auxiliar en cada uno de los cantones de la Provincia era como puede verse en la tabla 1. Cada uno de estos batallones tenía la obligación de velar por el bienestar y la seguridad de 130.258 habitantes, que era la población con la que contaba la Provincia de Cartagena según el censo de $1835 .{ }^{25}$

TABLA $1^{26}$

\begin{tabular}{|c|c|c|c|}
\hline Cantones & \multicolumn{2}{|r|}{ Batallones } & Plazas \\
\hline \multirow{2}{*}{ Cartagena } & Artillería & Número $1 .^{\circ}$ & 670 \\
\hline & Infantería & Número $1^{\circ}$ & 944 \\
\hline Barranquilla & Infantería & Número 2. ${ }^{\circ}$ & 881 \\
\hline \multirow{2}{*}{ Corozal } & Artillería & Número $3 .^{\circ}$ & 709 \\
\hline & Infantería & Número $4^{\circ}$ & 936 \\
\hline \multirow{2}{*}{ Chinú } & Artillería & Número $5^{\circ}$ & 717 \\
\hline & Infantería & Número $6 .^{\circ}$ & 232 \\
\hline \multirow{2}{*}{ Lorica } & Artillería & Número $7 .^{\circ}$ & 952 \\
\hline & Infantería & Número $8 .^{\circ}$ & 944 \\
\hline Mahates & Infantería & Número 9. ${ }^{\circ}$ & 1.308 \\
\hline Sabanalarga & Infantería & Número $10 .^{\circ}$ & 720 \\
\hline Soledad & Infantería & Número $11 .^{\circ}$ & 674 \\
\hline \multirow[t]{2}{*}{ San Andrés } & Artillería & 2 Compañías sueltas & 84 \\
\hline & & Total & 9.771 \\
\hline
\end{tabular}

25 BBC, SPC, Cartagena, 2 de agosto de 1840.

26 Ibidem, BBC, SPC, Cartagena, 19 de septiembre de 1847. 


\section{Guardias Nacionales: pedagogía y educación del ciudadano}

Esta Guardia era un espacio de sociabilidad y pedagogía política. Sus miembros debían reunirse los segundos y cuartos domingos de cada mes para recibir ejercicios de carácter doctrinal, en los que se les enseñaba, además del manejo de las armas, reglas de comportamiento, instrucción cívica, deberes y derechos del ciudadano e indudablemente el sentido de pertenencia y lealtad hacia la patria. ${ }^{27}$ Las proclamas y alocuciones de los gobernadores y los jefes políticos eran espacios a través de los cuales se les recordaba a las guardias nacionales el papel primordial que cumplían para la sociedad. En 1854, el gobernador de la Provincia de Cartagena, Rafael Núñez, se dirigía a la Guardia Nacional en los siguientes términos:

¡Ciudadanos armados! Yo os saludo en nombre de la provincia de Cartagena, como a los fieles representantes de su valor y de su patriotismo. La hora del peligro ha sido para vosotros la hora de la unión; y la Patria no ha tenido que pediros vuestra ayuda, porque vosotros se la habéis ofrecido y se la prestáis espontáneamente, así como lo hacían en los tiempos heroicos los hijos de Atenas, de Esparta y de Roma.

...iGuardias nacionales! Os habéis hecho dignos de este hermoso nombre desde que, abandonando vuestros hogares, habéis empuñado las armas en defensa de la República democrática. Un duelo a muerte se ha trabado entre la causa del absolutismo y la causa de la libertad; entre la dictadura de uno y la soberanía de todos; vosotros no habéis tardado en comprenderlo, y el estandarte tricolor os encuentra agrupados en torno suyo.

¡Ciudadanos armados! Que vuestro grito de guerra sea éste: ¡iViva la Constitución!! ¡iViva la República!!28

De igual forma, por medio de canciones también se alentaba a los ciudadanos de las guardias nacionales y se intentaba fortalecer su valor. En 1842 circuló en Cartagena la siguiente canción en la que se destacaba el papel desempeñado por los miembros de la guardia nacional en la victoria de una batalla. Algunas de sus estrofas expresaban:

Valerosos campeones del Pueblo! Orgullosos la frente alzad:

Vuestros altos deberes cumplisteis: dignos sois de corona inmortal.

Ya a la margen del horrible abismo, ¡socorredme! La Patria os gritó

Y a su voz presurosos corristeis, y salvada la Patria quedó.

...Vuestras almas no arredra el peligro; de los vientos domáis el furor:

Que la muerte es corona de gloria, al que lidia por Patria y Honor.

27 BBC, La Democracia, Cartagena, 9 de enero de 1851.

28 Corrales, 1999, p. 137. 
Más por fin a tan altos nobles esfuerzos.

Gratitud, gratitud a los bravos que adquirieron tan alto blasón!

¡Gratitud al experto guerrero que su bélico arrojo guió!

¡Alabanza a su heroica civismo!, ¡alabanza a su heroico valor! ${ }^{29}$

Asimismo, la Guardia Nacional pretendía ser expresión de nociones modernas de representación. Albergaba en su normativa formas democráticas para la elección de la estructura de mando y según la ley todo guardia nacional era elector y elegible, quedando en manos del gobernador el nombramiento del jefe principal de cada cuerpo. La elección era secreta, por medio de boletas depositadas en las urnas ${ }^{30} \mathrm{El}$ estatuto de la organización de la Guardia Nacional local, en su capítulo 5..$^{\circ}$ referente a la elección de jefes y oficiales, establecía que las elecciones para oficiales de compañía se abrían, en cada distrito parroquial, el segundo domingo del mes siguiente en el que la gobernación hubiese recibido las listas por parte de los alcaldes y jefes políticos de los miembros pertenecientes a las guardias nacionales y duraban abiertas hasta el domingo inmediato inclusive; pero podrían cerrarse antes de este término si se hubiese agotado la lista de los que debían sufragar.

De igual forma, el jefe político en la cabecera del cantón y los alcaldes en los demás distritos, asociados de dos individuos nombrados y juramentados por dichos funcionarios, formarían la Junta que debía recibir los votos. Estos individuos debían estar en ejercicio de los derechos de ciudadanía y saber leer y escribir. La elección tenía por objeto votar por los oficiales de la Guardia Nacional local, para lo cual estaban obligados a sufragar todos los individuos que pertenecieran a ella en el distrito parroquial. Ocho días antes de abrirse las elecciones, se convocaría por medio de un bando a los individuos que debían sufragar, cuyo bando se repetiría el día que comenzaran las elecciones. Cada sufragante votaría sucesivamente por un número de individuos igual al de capitanes, tenientes y alféreces que debían elegirse, llevándose por separado el registro de las votaciones para cada uno de dichos empleos. Concluidas las elecciones, el que presidiera la Junta pasaría el registro de las elecciones al presidente del Cabildo del distrito. Seguidamente, ese gobierno local procedía a declarar la elección de cada oficial. Hechos los nombramientos, los comunicaba por oficio a cada uno de los nombrados y los hacía saber también a la autoridad política del distrito.

29 Posada Gutiérrez, 1929, p. 419.

30 Macías, 2003, p. 143. 
Para la elección de jefes y demás individuos de la plana mayor, el jefe político, o el alcalde en su caso, hacía citar a los oficiales el domingo inmediato al que fueron elegidos. Reunidos esos oficiales procedían en presencia del jefe político o del alcalde a elegir los jefes respectivos e individuos de la plana mayor. Para cada nombramiento se hacía una elección por medio de papeletas en las que estaba escrito el nombre del candidato. Seguidamente, el secretario del jefe político o el oficial que designara el alcalde recogía las papeletas y hacía enseguida el escrutinio con la ayuda de dos escrutadores, que nombraría de entre los mismos oficiales y publicado el resultado, se declaraba electo el que mayor número de votos hubiese reunido. En caso de empate en las elecciones de jefes y oficiales se decidía siempre por la suerte. La duración de los jefes y oficiales de la Guardia Nacional era de cuatro años y no se consideraba como impedimento para ser elegido ni para continuar en el destino el ser mayor de cincuenta años. ${ }^{31}$

Sin embargo, el hecho de que el nombramiento se hiciera por medio de elecciones no impedía que la Guardia Nacional se convirtiera en instrumento de las facciones o de los partidos políticos, ya que en ella ejercía una gran influencia el gobernador de la Provincia, que era su jefe máximo. De este modo, luego de la formación de los partidos políticos, liberal y conservador, y pese a que las guardias nacionales estaban conformadas por ciudadanos neogranadinos que tenían la obligación de defender los principios constitucionales, cada gobernador determinaba que en la selección de los cuerpos de mando de esta institución se tuviera en cuenta, antes que su patriotismo y su lealtad, su afiliación política. Inclusive, también se recomendaba tener en cuenta a que facción del partido político pertenecía.

Todo esto generaba una fuerte controversia en los sectores políticos de la provincia, que veían como la Guardia Nacional se convertía en espacio de disputa entre los partidos o las facciones. Atrás quedaban los principios filantrópicos de formación del buen ciudadano, garante de la libertad y del orden. Ejemplo de lo anterior fue denunciado en 1849 por el periódico El Porvenir. Según este informativo, luego de la elección de José Hilario López como presidente de la República el 7 de marzo de 1849, se inició por parte de los gobernadores una reorganización de las guardias nacionales. Sin embargo, señala El Porvenir, donde con más empeño se esmeró en poner en práctica el gobernador de la Provincia de Cartagena su pericia en el ramo administrativo, fue en el tratamiento sobre nombramientos de

31 BBC, SPC, Cartagena, 21 de octubre de 1849. 
comandantes y oficiales que debían dirigirla. Quería el gobernador que los jefes y oficiales de la Guardia Nacional fueran individuos identificados con los principios triunfantes del 7 de marzo. Para los editores del periódico:

Allí es donde el autor se penetra de ese santo puro amor que todo liberal rojo tiene por el sostén de sus principios; allí donde él, olvidándose de sí mismo, se acuerda solo de llevar a cima el laudable propósito concebido por ellos de excluir y arrojar en la noche del olvido los importantes servicios, la honradez, la integridad, las luces y conocimientos de los hombres que, aunque poseedores de tan recomendables cualidades, no hayan tenido sin embargo la cordura de alistarse en su bandera.

Lo que defendía el informativo era que las guardias nacionales estaban llamadas a sostener la Constitución y dar seguridad a las propiedades; y ese encargo podía desempeñarlo todo buen patriota, todo hombre amante de su país. Por eso juzgaban que al hacerse una mención especial de los individuos pertenecientes al partido del 7 de marzo, se hacía al resto de la comunidad la más grande injusticia, puesto que estando todos interesados en su propia conservación y en la de sus intereses, claro era que donde quiera que se viera a un patriota ahí se encontraba un buen guardia nacional. A renglón seguido el periódico enfatizaba:

\begin{abstract}
¿Cuáles son esos principios triunfantes del 7 de marzo?, ¿sobre qué base estriban? No los conocemos; pues por lo que se ve, la misma Constitución, las mismas leyes rigen que regían antes del 7 de Marzo; y en cuanto a principios administrativos, que son los únicos que podría variar el Presidente de la República, no sabemos cuáles sean los que se hayan inaugurado. Claro es, pues, que lo que debe entenderse por identificación con los principios triunfantes el 7 de Marzo, es el haber sido partidario del candidato que fue electo ese día; ¿y podrá esto ser justo, patriótico, decoroso siquiera? Para hacer evidente la injusticia de la exclusión que se pretende, basta observar que el mismo partido que se titula Liberal y que está hoy en el poder, se cuentan multitud de individuos que no estuvieron por el General López y que antes bien escribieron, charlaron y trabajaron a favor del Dr. Cuervo, votando como sufragantes parroquiales por la lista de los cuervistas..$^{32}$
\end{abstract}

Meses después, este mismo periódico titulaba su editorial "Abuso en las elecciones" para denunciar que un guardia nacional de artillería, en las elecciones para escoger los miembros del Cabildo de Cartagena, votó por los miembros del partido conservador y "hoy los jefes, siguiendo los embates de sus pasiones, lo amenazan con la destitución... parece como que

32 BBC, El Porvenir, Cartagena, 15 de septiembre de 1849. 
estos procedimientos son dignos de los rojos, que no de vergüenzas como debieran ser". ${ }^{33}$

Naturalmente, para nadie era un secreto que las guardias nacionales eran una institución clave en las elecciones. ${ }^{34} \mathrm{Al}$ estar conformada por ciudadanos activos, con derechos a elegir y ser elegidos y primando en la Nueva Granada una ciudadanía de carácter censitario, donde una buena parte de la población estaba excluida del derecho al voto, los guardias nacionales eran una instancia de poder. Por ello, en cada elección que se realizaba en el país, en las provincias, en los cantones o en los distritos parroquiales; los candidatos, las facciones y los partidos utilizaban cualquier instrumento para contar con el apoyo de los guardias nacionales. Y así lo entendían ellos.

Al gozar en el interior de sus comunidades de reconocimiento y valía social por ser la fuerza defensora de la legitimidad estatal, de los derechos de los ciudadanos y de las libertades individuales, las guardias nacionales hacían explícitos a través de la prensa, volantes, hojas sueltas y otros, los candidatos a los que apoyaban y por los que depositarían sus votos en las urnas con el fin de persuadir a la población. Verbigracia, en 1851 y en medio de las elecciones que se celebrarían para escoger a la persona que reemplazaría a José Hilario López en la Presidencia de la República, la plana mayor y oficialidad del $4 .^{\circ}$ batallón de Guardia Nacional del cantón de Chinú, publicó a través de hojas volantes y por el periódico La Democracia la siguiente declaración:

En la Villa de Chinú, cabecera del cantón del mismo nombre en la Provincia de Cartagena...reunidos la plana mayor y oficialidad del $4 .^{\circ}$ batallón de guardia nacional con el exclusivo y plausible objeto de conferenciar y uniformar su opinión sobre el ciudadano en cuyo favor se debe obrar para que suceda en el alto puesto de Presidente de la República en el $6 .^{\circ}$ periodo constitucional a José Hilario López...se procedió a discutir la siguiente proposición: ¿Cuál es el candidato que para Presidente de la República adopta en el próximo periodo constitucional el batallón?

... Respuesta: el $4 .^{\circ}$ batallón de guardia nacional en la Provincia de Cartagena adopta por candidato para la Presidencia a José María Obando. En su consecuencia, todos y cada uno de los que suscribimos nos comprometimos de nuestra espontánea voluntad a trabajar en nuestros respectivos domicilios y por todos los medios legales en pro de dicha candidatura. ${ }^{35}$

33 Ibidem, Cartagena, 5 de diciembre de 1849.

34 Peralta, 1999, pp. 231-252.

35 BBC, La Democracia, Cartagena, 6 de julio de 1851. 
Sin embargo, no todo era color de rosa en las guardias nacionales. Desde el mismo momento de su organización, atravesarían una serie de vicisitudes como la falta de recursos económicos y la poca disposición de los ciudadanos a hacer parte de las mismas, como lo veremos a continuación.

\section{Problemas de las guardias nacionales: Falta de recursos humanos y materiales}

La falta de recursos económicos era una constante en las guardias nacionales. Por lo general, sus miembros carecían de uniformes o de espacios para guardar las pocas armas con las que contaban. Lo normal era que los miembros de la plana mayor de los batallones mantuvieran en sus casas las armas pertenecientes a estos cuerpos. En el año de 1839, el jefe instructor del batallón de artillería de la Guardia Nacional del cantón de Barranquilla, Ramón Antigüedad, presentó al gobernador un informe sobre el estado en que se encontraba el armamento para que dictara las medidas que creyera convenientes. Según el jefe instructor, cuando se disolvió la compañía que existía en el distrito de Santo Tomás, el armamento quedó a cargo de su capitán y permanecía en su casa, pero este le indicó que dispusiera de él, puesto que ya no podía tener ocupado un cuarto de su casa para conservarlo. Respecto de este armamento, mandó un oficio a la gobernación de la Provincia pidiendo que decretase de donde debía salir el gasto para transportarlo a Galapa, porque aquella media compañía no tenía el que necesitaba para su instrucción; pero esta comunicación que fue enviada en noviembre, hasta ese momento no había tenido contestación. Lo misma situación se repetía en Soledad y Baranoa.

Según Ramón Antigüedad, el armamento podría estar en las cárceles de los lugares pero careciendo casi todas de aposento separado, tendría que estar a disposición de los presos; agregándose a esto que las clases veteranas no existían en los pueblos, excepto en Soledad, donde había cuatro veteranos a solicitud de la jefatura política. Por supuesto, sin quien respondiera de él. Entonces, las soluciones presentadas por el jefe instructor consistieron en proponer que el gobierno pagara en cada pueblo donde hubiera milicianos, una casa para que sirviera de cuartel y se depositara en ella el armamento a cargo de los individuos veteranos que debían instruir a la compañía y que ellos subsistieran en el lugar o que el fusil se le diera a cada 
miliciano para que lo cuidara en su casa y se presentara con él al ejercicio; pero esto último también tenía sus dificultades para la conservación del armamento. Una de ellas era que los milicianos emplearían en la casa y en otros usos particulares los fusiles, otra que ellos cambiaban de vecindario con frecuencia, algunos hacían largos viajes o podían fallecer sin que se supiera a quien dejaban encargado el armamento..$^{36} \mathrm{~A}$ estas solicitudes, la respuesta que obtuvo fue que no se adoptaría ninguno de los medios que indica el jefe instructor porque:

Desde el año de 1831 hay en Barranquilla, un batallón de guardia nacional y el armamento de las compañías de los pueblos lo han tenido en sus casas los comandantes de ellas, en esto no veo otra cosa sino un interés por el cuerpo a que pertenecen, mayormente cuando no les resulta sino una pequeña molestia, la cual han sobrellevado y pueden continuar sobrellevando los oficiales de guardia nacional siempre que estén animados de sentimientos patrióticos, como ha sucedido hasta hoy, en tal virtud no hay motivo alguno que obligue a hacer otras variaciones... ${ }^{37}$

Sin embargo, este era el menor de los problemas que padecían las guardias nacionales de la Provincia. El mayor consistía en la falta de ciudadanos que quisieran enrolarse en esta institución. En 1835, el gobernador señalaba en su informe a la Asamblea que la Guardia Nacional estaba compuesta de dos batallones y un escuadrón; el primero de infantería situado en Cartagena, el segundo de artillería en Barranquilla y el tercero de caballería, en Corozal. Sus jefes manifestaban todo el esmero posible para la instrucción de los cuerpos; éstos tenían una disciplina regular "aunque no en el grado posible, porque por una fatalidad, nuestros pueblos, no obstante su adhesión a la causa de la independencia y las repetidas pruebas que han dado en diversas ocasiones de valor y de heroicidad; tienen aversión puntual al servicio continuado y pasivo". ${ }^{38}$ Doce años después, otro gobernador presentaba el mismo cuadro lastimoso sobre las guardias nacionales y enfatizaba las causas y las zonas en que se mostraba mayor aversión hacia esta institución:

La organización e instrucción de los cuerpos de guardia nacional auxiliar se adelanta cuanto lo permiten los innumerables inconvenientes que para ello se presentan, nacidos unos de las disposiciones vigentes sobre esta materia; otros de poca cooperación en algunas autoridades locales, y principalmente de la repugnancia general con que

36 AHC, Barranquilla, 16 de enero de 1839.

37 Idem.

38 BBC, Constitucional de Cartagena, Cartagena, 30 de septiembre de 1835. 
se mira este servicio en los pueblos del campo, que ignorando el verdadero objeto de esta institución se alarman siempre que se trata de una organización y disciplina. ${ }^{39}$

Es necesario aclarar que no solamente eran los hombres del campo los que se mostraban renuentes a prestar el servicio militar como guardias nacionales, sino que también era una constante en las principales ciudades del país como Bogotá, Cali, Medellín y Cartagena. En 1853, el presidente de la República le aclaraba al Congreso:

Yo no debo ocultaros las dos principales causas de la situación poca ventajosa de la Guardia Nacional...desde que comienza el alistamiento de los cuerpos de la Guardia Nacional, comienza también a ser visible, en la generalidad de los casos, la repugnancia a inscribirse en ellos, de las personas ricas o acomodadas, o que, por cualquier otro título, tienen una buena posición social. Las clases pobres, compuesta de labradores, artesanos y jornaleros, observando aquellas tendencias, y teniendo en cuenta que la ley no distingue entre fortunas y rangos para la formación de esos cuerpos, se sienten heridos por la desigualdad que quiere establecerse y toman el partido de oponer la fuerza de inercia al llamamiento de la autoridad. ${ }^{40}$

Aunque la legislación establecía que era un deber de todo ciudadano formar parte de las guardias nacionales, era muy frecuente que muchos violaran esta disposición. Diferentes mecanismos eran utilizados por los ciudadanos de las clases acomodadas de la Nueva Granada para evitar cumplir con el deber de prestar el servicio militar. Uno era manifestando ser extranjero debido a que éstos estaban exceptuados. Otros se presentaban por medio de falsificaciones otorgadas por médicos y curas o utilizando la influencia de personas del gobierno o militares. En 1843, el Semanario de la Provincia de Cartagena resaltaba:

Hoy terminan los alistamientos para la guardia nacional en esta ciudad. No serán pocos los que hayan dejado de alistarse, o aumentándose la edad, o que estén preparándose para comprobar que son cojos aunque se les vea correr con sus dos pies; pero es preciso que las autoridades no se dejen burlar por éstos últimos y desprecien toda certificación que no sea de inutilidad notoria, como lo requiere la ley. ..Es necesario hacer entender al pueblo, que ni las riquezas, ni una corbata alta dan ningún privilegio para no servir a su país. Si ha de continuar la burla de las certificaciones falsas de médicos y curas, si las amistades han de poder más que las leyes, mejor será que no haya guardia nacional. ${ }^{41}$

39 BBC, SPC, Cartagena, 19 de septiembre de 1847.

40 BBC, El Patriota, Cartagena, 24 de marzo de 1853.

41 BBC, SPC, Cartagena, 17 de diciembre de 1843. 
Entre las causas por las que muchos ciudadanos se negaban a integrarse en las guardias nacionales se encontraban las excepciones que se hacían a los empleados públicos y que a los ojos de los demás eran injustas. ${ }^{42}$ Además, como eran frecuentes las guerras civiles y los trastornos políticos, existía un temor entre los sectores acomodados a perder la vida. Según Flavia Macías, la guerra era vista como un castigo para la "gente decente", que percibía que sus deberes cívicos estaban vinculados a la industria y a la vida pública. En este caso, la noción de defensa y mantenimiento del orden interno se ligaba a la capacidad de garantizar el desarrollo de la economía y la política local y al cumplimiento de las leyes establecidas, más que al servicio militar en la guerra, el cual entendían como una obligación inherente a aquellos sectores que aún debían "pagar con su sangre" el acceso y el derecho a la ciudadanía. ${ }^{43}$

Entonces, si muchos ciudadanos, especialmente los de las clases acomodadas, evitaban prestar el servicio militar como guardias nacionales, ¿quiénes acudían al alistamiento? En 1851, el artesano y uno de los fundadores de la Sociedad Democrática de Bogotá, Ambrosio López, a través de un escrito titulado El Desengaño, respondía este interrogante de la siguiente manera:

$\mathrm{Y}$ acordaos que los que fueron al matadero, no fueron de las clases privilegiadas: recordad, repito: que los muertos e inválidos todos fueron de los milicianos, es decir, los sastres, los zapateros, albañiles, carpinteros, herreros y labradores, porque para estas gentes es que en estos gobiernos democráticos, se organizan las Guardias Nacionales, y no para los que se reputan como patricios, que nosotros somos plebeyos. ${ }^{44}$

Es decir, los artesanos de Bogotá eran uno de los grupos sociales que más hombres aportaba para el funcionamiento de las guardias nacionales en su Provincia. No obstante, la pregunta que nos surge es ¿sucedía lo mismo en la provincia de Cartagena? La respuesta es sí. Pero, para poder entender esta participación, es necesario conocer los cambios sociales y políticos vividos por los artesanos con y después de la independencia.

\section{Artesanos, guardias nacionales y ciudadanía en Cartagena}

Los artesanos hicieron de la Guardia Nacional un nuevo mecanismo para fortalecer el protagonismo social y político que venían construyendo

42 Ibidem, Cartagena, 7 de abril de 1844.

43 Macías, 2003, p. 149.

44 López, 1985, p. 79. 
desde la segunda mitad del siglo XVIII. En efecto, al igual que lo que sucedía en otras colonias americanas, durante el último siglo de dominación colonial sectores del artesanado del Nuevo Reino de Granada alcanzaron un protagonismo social y político significativo gracias a las condiciones impuestas por el mestizaje al reacomodo del orden social, en especial a la valoración social positiva de las personas y familias gracias a la construcción de una vida meritoria, tanto personal como familiar, a base de esfuerzos, sacrificios y la proyección social de una conducta aceptada y valorada por los demás. ${ }^{45}$ Para los mestizos y mulatos (y la mayoría de los artesanos pertenecían a estas condiciones socio-raciales) el pasado como nicho de prestancia no significaba nada y su proyecto de vida estaba proyectado hacia el futuro. ${ }^{46}$ En consecuencia, al lado de la tradicional prestancia social determinada por la raza, los abolengos y los orígenes familiares, paulatinamente fue surgiendo otra, la determinada por el autoesfuerzo, por los méritos y el reconocimiento social logrados gracias a la práctica de unas virtudes que el conjunto social consideraba como dignas y honorables. ${ }^{47}$ Estudios recientes ${ }^{48}$ muestran que desde el siglo XVIII los sectores subalternos optaron por el diseño de estrategias individuales y familiares para alcanzar el propósito de salir del estado de indiferenciación social, el cual fueron alcanzando gracias a que las transformaciones en la distribución de la economía del honor confluyeron con algunas de las políticas reformadoras de los Borbones (verbigracia, la reforma militar que abrió las milicias a los mulatos ${ }^{49}$ y las reformas del trabajo artesanal ${ }^{50}$ ) y con la formación de franjas de artesanos prestantes gracias a la calidad de sus trabajos. ${ }^{51}$ Estos logros permitieron que las elites neogranadinas vieran en muchos artesanos una especie de sector intermedio gracias a la calidad de sus trabajos, la honradez y la vida decorosa que llevaban.

45 Solano, 2010; Solano, 2010a, pp. 193-213.

46 Garrido, 1999, pp. 99-121; Echeverri, 1998, pp. 46-63 у 2003, pp. 97-112.

47 Para finales de la colonia nuevos elementos ideológicos y científicos introdujeron una visión más antropológica e histórica del hombre, concebido ahora como un ser en construcción, y por tanto posible de perfección. Solano, 2010; Solano, 2010b, pp. 193-213; Solano y Flórez, 2008, pp. 125-144. 48 Helg, 2004, pp. 91-120, 147-154; Conde, 2009, pp. 29-58.

49 Kuethe, 1994, pp. 177-192; Marchena, 2005, pp. 31-100; Pérez, 2008, pp. 315-336.

50 Archivo General de la Nación (Colombia), "Instrucción General para los Gremios [1777]", en Colonia, miscelánea, tomo III, folios 287-313; Mayor, 1997, pp. 69-98, 99-216.

51 Esa exigencia también se cimentaba en los viejos discursos sobre las diferencias entre las artes nobles y los oficios viles y sus correspondientes prácticas sociales, distinción que permitía a los ejercitantes de determinados trabajos (platería, herrería, ebanistería, pintura, sastres, maestros de obra, y los tipógrafos y mecánicos en el siglo XIX) diferenciarse del resto de los menestrales gracias al conocimiento y la dedicación que demandaban sus oficios y a la prestancia que les procuraban. Sewell, 1992, pp. 41-50, 100-109; Pérez, 2007, pp. 189-214. 
Los artesanos arribaron a los albores de la época republicana anhelando reconocimiento social, y la escasa importancia que concedían al pasado social encajó con los propósitos del discurso liberal republicano de desarraigar a los individuos del pasado gracias a la condición de la ciudadanía. ${ }^{52}$ De ahí que los artesanos-milicianos jugaran un papel trascendental en el logro de la Independencia. ${ }^{53}$ Ya para las primeras décadas del XIX los artesanos se habían consolidado, al lado de otros grupos sociocupacionales como una capa media de la sociedad, facilitándoseles el acceso al derecho de ciudadanía. ${ }^{54}$ En ese sentido, como para formar parte de la Guardia Nacional era necesario gozar de los derechos de ciudadanía, y como poseían, además, una larga tradición militar, uno de los grupos sociales que más hombres aportaba para el alistamiento y conformación de la misma en la Provincia de Cartagena era el de los artesanos, principalmente los tipógrafos, sastres, plateros, fondistas y maestros de obra. Los artesanos constituían la columna vertebral de la organización militar más importante, después del ejército. ${ }^{55}$

Ahora bien, ellos eran conscientes de la desigualdad social y racial que existía al interior de esta institución en el momento de su conformación y también sabían que eran ellos quienes más hombres aportaban, como lo vimos reflejado en la cita de Ambrosio López en 1851. En esa misma dirección se expresaba el órgano oficial de la Provincia de Cartagena cuando argumentaba que "es una injusticia se exceptuase del servicio a los ricos y que se cause mayor perjuicio, al infeliz artesano a quien se distrae de su trabajo obligándolo a servir en la guardia nacional que al empleado que por prestar semejante servicio no dejaría de ganar su sueldo". ${ }^{56}$

Sin embargo, aunque en el siglo XIX el servicio de las armas dejó de ofrecer a los artesanos las mismas posibilidades de movilidad social que durante el periodo colonial, permitió que lograran un reconocimiento por parte de los demás sectores de la sociedad cartagenera, convirtiéndose en un grupo visible que gozaba de prestancia y respeto. Eran vistos como

52 Teitelbaum, 2008, pp. 177-274; Amaro, 2008, pp. 165-208; Garcia-Bryce, 2008, pp. 121-166.

53 Algunos de ellos fueron enviados en el cuerpo de veteranos del Fijo de Cartagena a Bogotá como voluntarios para enseñar el manejo de las armas a los oficiales de ésta ciudad. A esta especie de academia concurrían varios señores del comercio y muchos jóvenes, "a quienes los de Cartagena llamaban los paisanos, así como éstos llamaban a aquellos los chungos, sin duda por ser casi todos gente de color". Espinosa, 1983, p. 32.

54 Sowell, 2006, pp. 143-171; Garcia-Bryce, 2008, pp. 121-166.

55 Gutiérrez, 1999, p. 187.

56 BBC, SPC, Cartagena, 7 de abril de 1844. 
hombres patriotas ya que constituían el único sector social que sistemáticamente sacrificaba su vida en aras de la República. ${ }^{57}$ En ese sentido, las instituciones militares durante el siglo XIX se convirtieron en un espacio que permitiría el ascenso de los sectores medios y bajos de la población. Por ejemplo, en mayo de 1840 el periódico El Tiempo publicó una serie de artículos que reflejaban una disputa entre el zapatero Manuel Pereira Plata y el agricultor Blas José de la Madrid, por el nombramiento de éste último como administrador de recaudación del Cantón de Chinú. Aunque parte de los argumentos emitidos por ambos ciudadanos se situaban en el plano de las recriminaciones personales, por ejemplo De la Madrid, le señalaba a Pereira Plata que había sido "expulsado del ejército por enemigo de los principios republicanos, mientras yo, no miserable zapatero, pues apenas se usar zapatos y no hacerlos, me ejercito el alguna honesta ocupación para vivir y se algún arte mecánico y labrar la tierra", llama poderosamente la atención la forma como termina defendiendo sus actuaciones Blas José de la Madrid. Para él los diversos cargos que había desempeñado durante su vida se debían básicamente a su participación en la guerra de la Independencia y en la defensa de la legitimidad estatal a través del servicio de las armas:

Desde 1820 en que estaba muy joven pude llevar sobre mis hombros y llevé un fusil a favor de la Independencia nacional; más tarde habiendo merecido la charretera de oficial y servido en el ejército protector hasta el restablecimiento legítimo, fui destinado de jefe de la ronda volante, en que permanecí hasta que se extinguió; en el tiempo que no he servido a la República empleos militares, lo he hecho en los concejiles, ya de juez parroquial de San Onofre, mi antiguo vecindario, regidor del cabildo de Tolú, concejero y juez cantonal de esta Villa... ${ }^{58}$

Al igual que De la Madrid, los artesanos en Cartagena serían recompensados por su activa participación en las instituciones militares de la ciudad. Muchos de ellos se destacaron por ocupar puestos de mando dentro de la Guardia Nacional de la Provincia como fue el caso del tipógrafo José María Pasos, quien en 1846 envió una representación al presidente de la República por la negativa que se le dio a su petición de que le fuese pagada la suma de noventa pesos por un caballo y una silla que en 1841 facilitó para el servicio de las tropas que constituían la guarnición de Cartagena. La negativa del Ejecutivo se debió a que Pasos firmó el acta de rebelión de

57 Ibidem, Cartagena, 7 de abril de 1849.

58 BBC, El Tiempo, Cartagena, 24 de mayo de 1840. 
la Provincia de Cartagena y cooperó a favor de la revolución que terminó con la deposición del gobernador. Aunque Pasos no negó nada, se defendía argumentando que, al igual que él, muchos ciudadanos lo habían hecho y a ellos si les habían devuelto sus capitales, y agregaba:

Suponiendo que el acto me aparejase alguna responsabilidad, ¿no es un hecho cierto, que el supremo gobierno por mis esfuerzos y servicio en el restablecimiento del orden de esta provincia, me expide en abril de 1842 un diploma de Capitán de Guardia Nacional y más tarde me asciende a sargento mayor efectivo, confiriéndoseme a la vez el segundo mando del Primer Batallón de Infantería de Guardia Nacional de esta Provincia? $?^{59}$

Cinco años después, en 1851, los artesanos de Cartagena organizados en la Guardia Nacional jugarían nuevamente un importante papel en la guerra civil que enfrentó a los partidos políticos liberal y conservador. La aprobación de algunas medidas consideradas anticlericales por los conservadores, sirvieron de excusa para que este partido se levantara contra el gobierno de José Hilario López. Sin embargo, el motivo principal de esta rebelión y su común denominador en las diversas regiones del país, fue el deseo de romper el dominio político del partido liberal y restaurar el control del partido conservador sobre el gobierno nacional. ${ }^{60}$ Esto determinó que los artesanos, organizados en las denominadas Sociedades Democráticas, salieran en defensa de los liberales debido a que dos años antes habían establecido una alianza con este partido. ${ }^{61}$ Durante el gobierno de José Hilario López (1845-1849), se protegió y estimuló a las Sociedades Democráticas como un importante instrumento de gobierno. Durante este periodo proliferan de tal manera que prácticamente existieron en las principales ciudades del país.

La rebelión fue fácilmente derrotada por los ejércitos del Gobierno con la ayuda brindada por las guardias nacionales y las sociedades democráticas. Para reprimir la rebelión conservadora en el Cauca y Antioquia, las clases populares de las sociedades democráticas organizadas en unidades militares habían suministrado parte de la fuerza militar. ${ }^{62}$ En Cartagena, la situación fue similar. Los artesanos, organizados en la Sociedad Democrática, también desempeñaron un importante papel. El primer paso

59 BBC, SPC, Cartagena, 1 de noviembre de 1846.

60 Palacio y Safford, 2002, p. 384.

61 Colmenares, 1968, pp. 134-137.

62 Palacio y Safford, 2002, p. 400. 
dado por esta sociedad para la intervención en la guerra fue el 17 de julio, cuando fue convocada extraordinariamente por las noticias llegadas del interior del país. El objeto de la reunión era deliberar acerca de lo que debía hacerse en defensa del Gobierno, ahora que el partido conservador promovía la rebelión en distintas provincias de la Nueva Granada. Luego de varias horas de debate de los miembros de la Sociedad y alcanzado un consenso, el artesano y capitán de la Guardia Nacional de la Provincia de Cartagena, Julián Moré, redactó una carta a nombre de la Sociedad dirigida al presidente de la República en los siguientes términos:

Ciudadano Presidente: los miembros de la sociedad democrática de Cartagena os ofrecen solemnemente sus servicios en la presente emergencia de la Nación como en cualquiera otra en que pueda encontrarse. Además... cumpliremos con todo el entusiasmo de nuestro corazón y con el denuedo de verdaderos republicanos, los deberes consignados en el artículo 6 de la Constitución, en este caso prestando el servicio militar como Guardias Nacionales o como Soldados regulares. El deber que tenemos los miembros de la sociedad democrática es sostener el orden público y defender la administración del 7 de Marzo, prestando su apoyo a las autoridades legalmente constituidas. $^{63}$

Después de este acto, los artesanos, quienes en gran mayoría conformaban la Sociedad Democrática de Cartagena, se alistaron en el servicio militar en defensa del Gobierno. En una proclama del comandante general del Departamento militar del Atlántico a la Guardia Nacional auxiliar recordaba:

Ciudadanos de la Guardia Nacional Auxiliar: Muchas veces os he oído expresar en las sesiones de la Sociedad Democrática, de que son miembros la mayor parte de vosotros, el deseo que os anima para defender las instituciones... Vosotros como auxiliares, hoy en servicio activo, estáis obligado a cumplir estrictamente los deberes de un soldado, dando el ejemplo, las promesas de sometimiento a todo cuanto sea ordenado relativamente al servicio de las armas. ${ }^{64}$

A pesar de que la rebelión conservadora fue derrotada a finales de 1851, el medio batallón de la Guardia Nacional de artillería de Cartagena continuó funcionando hasta mayo de 1853 y, además, aunque después de "pacificada" la República, todos los demás cuerpos de ésta clase se restituyeron a sus hogares, el de Cartagena continuó prestando sus servicios aun

63 BBC, La Democracia, Cartagena, 21 de julio de 1851.

64 Idem. 
más allá del círculo de su guarnición llegando hasta Honda conduciendo armamento y reclutas. Finalmente, éste fue desacuartelado en 1853 por el gobernador de la provincia, Juan José Nieto, quien en apartes de su proclama recalcaba:

\begin{abstract}
Veintidós meses hacía que este cuerpo, compuesto de artesanos y hombres ocupados, prestaba sus servicios a la Nación...

Conciudadanos de la guardia nacional: ...vengo a nombre del gobierno a daros las gracias por la abnegación y patriotismo, con que por tanto tiempo, habéis abandonado vuestras obligaciones domésticas, y aun vuestro bienestar, para cumplir con uno de los sagrados deberes a que estamos constituidos todos los granadinos, el de tomar, como al presente, las armas en defensa de la República, lo cual es un nuevo mérito que habéis adquirido para con ella. ${ }^{65}$
\end{abstract}

\title{
Conclusiones
}

En este artículo hemos mostrado el papel activo desempeñado por los artesanos en la Guardia Nacional de la provincia de Cartagena. Esta participación se debía a que este grupo social articuló un discurso que se caracterizaba por ser un republicanismo de corte popular, entre cuyos principios se encontraban que el objetivo último de cualquier sociedad política debía ser la preservación del bien común, que se traducía en que los ciudadanos de una República necesitaban subordinar sus fines privados. ${ }^{66}$ Este discurso era materializado por los artesanos de la Provincia de Cartagena con su activa participación en la Guardia Nacional, toda vez que el derecho de ciudadanía coincidía con el derecho y el deber de llevar armas, dando así muestras de virtud cívica republicana, por ser capaces de sacrificar pasiones, trabajo y vida privada cuando se trataba de acudir en defensa de la Patria. ${ }^{67}$

Naturalmente esta participación de los artesanos en el citado cuerpo encontró su recompensa en el amplio reconocimiento social y político que disfrutaban y que se traducía en el nombramiento de mucho de ellos en cargos públicos. Por ejemplo, en 1850 el periódico El Porvenir hacía alusión a esta activa participación de los artesanos en la vida pública de Cartagena. El informativo sostenía que la vida política de los artesanos seguía siendo

65 Ibidem, Cartagena, 2 de junio de 1853.

66 Daitsman, 2003, p. 87; Sanders, 2004, pp. 18-57.

67 Peralta, 1999, p. 234. 
la misma desde la independencia, con la diferencia de que si en el marco de los gobiernos conservadores se les adjudicaba un cargo público, podían ejercerlo con la libertad e independencia, cosa que no estaba ocurriendo en los gobiernos liberales donde sólo son “...ciegos instrumentos de que los malvados usan para engrandecerse y de quienes se burlan, y a quienes desprecian más tarde cuando ya no los necesitan" ${ }^{68}$ Lo anterior corrobora lo defendido en este artículo: el papel fundamental jugado por los artesanos en la vida política de la Provincia de Cartagena durante la primera mitad del siglo XIX.

Recibido el 19 de mayo de 2009 Aceptado el 21 de octubre de 2010

\section{Bibliografía}

Luís Alarcón: "Formando ciudadanos", en: Ensayos de historia, educación y cultura, Barranquilla, Universidad del Atlántico, 2000, pp. 25-55.

- "Construir la República y redefinir el pueblo. El discurso político en los manuales escolares colombianos del siglo XIX", Historia Caribe, 7, Barranquilla, 2002, pp. 40-55.

René Amaro: "Artesanía y ciudadanía en Zacatecas del siglo XIX", en René Amaro (coord.): Relaciones de poder, procesos sociales y conflictos políticos en Zacatecas. De la colonia a la etapa porfirista, Zacatecas, Universidad Autónoma de Zacatecas, 2008, pp. 165-208.

Antonio Annino: "Ciudadanía 'versus' gobernabilidad Republicana en México", en Hilda Sabato, (coord.): Ciudadanía política y formación de las Naciones. Perspectivas históricas de América Latina, México, Fondo de Cultura Económica, 1999, pp. 62-92.

David Bushnell: Aspectos de la historia electoral colombiana, Tunja, Universidad Pedagógica y Tecnológica de Colombia, 1975.

Marcelo Carmagnani y Alicia Hernández: "La ciudadanía orgánica mexicana, 1850 -1910”, en Hilda Sábato (coord.): Ciudadanía política y formación de las naciones, 1999, pp. 371-404.

Germán Colmenares: Partidos políticos y clases sociales en Colombia, Medellín, La Carreta, 2008.

Jorge Conde: "De vasallos a ciudadanos: mecanismos de transmisión y reproducción de los valores cívicos en Colombia en los umbrales de la Nación”, en

68 BBC, El Porvenir, Cartagena, 5 de febrero de 1850. 
Memorias del IV Seminario Internacional de Estudios del Caribe, Barranquilla, 1999, pp. 120-140.

- "Representaciones y catecismos políticos en el origen de la pedagogía de la Nación", en Ensayos de historia, educación y cultura, Barranquilla, Universidad del Atlántico, 2000, pp. 56-80.

- Buscando la Nación. Ciudadanía, clase y tensión racial en el Caribe colombiano, 1821-1855, Medellín, Universidad del Atlántico-La Carreta, 2009.

Manuel E. Corrales (comp.): Anales del Estado de Bolívar, Cartagena, Gobernación de Bolívar, 1999.

Edwin Cruz: "El papel de los artesanos en la formación de lo público-político durante el siglo XIX colombiano", en Leopoldo Múnera y Nathaly Rodríguez (eds.): Fragmentos de lo público-político Colombia siglo XIX, Bogotá, Universidad Nacional-La Carreta Eds., 2009, pp. 255-297.

José Carlos Chiaramonte: "Ciudadanía, soberanía y representación en la génesis del Estado argentino", en Hilda Sábato (coord.): Ciudadanía política y formación de las naciones, 1999, pp. 94-118.

Andy Daitsman: "Diálogos entre artesanos. Republicanismo y liberalismos populares en Chile decimonónico", Revista Universum, 13, Santiago de Chile, 1998, pp. 80-100.

Malcolm Deas: "Algunas notas sobre la historia del caciquismo en Colombia", en Del poder y la gramática y otros ensayos sobre historia, política y literatura colombianas, Bogotá, Taurus, 2006, pp. 209-234.

Fernando Escalante: Ciudadanos imaginarios, México, El Colegio de México, 1993.

Patricia Echeverri: "El honor del mestizo", Memorias, 2, Bogotá, 1998, pp. 46-63.

- "Nuevas indagaciones acerca de la identidad del mestizo", Anuario Colombiano de Historia Social y de la Cultura, 30, Bogotá, 2003, pp. 97-112.

José María Espinosa: Memorias de un abanderado. Recuerdos de la Patria Boba, 1810-1819, Bogotá, Plaza y Janés, 1983.

Roicer Flórez: "Ciudadanos y vecinos: un acercamiento al proceso de construcción del ciudadano en Cartagena durante el siglo XIX”, Historia Caribe, 11, Barranquilla, 2006, pp. 135-152.

Inigo Garcia-Bryce: República con ciudadanos: los artesanos de Lima, 18211879, Lima, Instituto de Estudios Peruanos, 2008.

Margarita Garrido: "Honor, reconocimiento, libertad y desacato: sociedad e individuo desde un pasado cercano", en Luz G. Arango, Gabriel Restrepo y Carlos E. Jaramillo (eds.): Cultura, política y modernidad, Bogotá, Universidad Nacional, 1999.

Fernán González: "Legislación y comportamientos electorales: evolución histórica”, Para leer la política. Ensayos de historia política colombiana, tomo 1, Bogotá, Cinep, 1997, pp. 70-95. 
Richard Graham: "Ciudadanía y jerarquía en el Brasil esclavista”, en Hilda Sábato (coord.): Ciudadanía política y formación de las Naciones. Perspectivas históricas de América Latina, 1999, pp. 345-401.

François-Xavier Guerra: "El Soberano y su Reino: Reflexiones sobre la génesis del ciudadano en América Latina”, en Hilda Sábato (coord.): Ciudadanía política y formación de las naciones, 1999, pp. 33-61.

Francisco Gutiérrez: "La literatura plebeya y el debate alrededor de la propiedad en la Nueva Granada, 1849-1854”, Ibidem, pp. 181-200.

Veronique Hébrard: “¿Patricio o soldado: Que 'uniforme’ para el ciudadano? El hombre en armas en la construcción de la Nación (Venezuela 1. ${ }^{\mathrm{a}}$ mitad del siglo XIX)", Revista de Indias, LXII-225, Madrid, 2002, pp. 429-462.

Aline Helg: Liberty and equality in Caribbean Colombia 1770-1835, Chapel Hill, The University North Carolina Press, 2004.

Marta Irurozqui: "La conquista de la ciudadanía. Artesanos y clientelismo político en Bolivia, 1880-1925", Tiempos de América, 3-4, 1999a, pp. 99-117.

— "iQue vienen los mazorqueros! Usos y abusos discursivos de la corrupción y la violencia en las elecciones bolivianas, 1884-1925”, en Hilda Sábato (coord.): Ciudadanía política y formación de las naciones, 1999b, pp. 295-317.

- “Ciudadanos armados o traidores a la Patria? Participación indígena en las revoluciones bolivianas de 1870 y 1899”, Iconos. Revista de Ciencias Sociales, N. ${ }^{\circ}$ 26, Quito, 2006, pp. 35-46.

Allan Kuethe: "Flexibilidad racial en las milicias disciplinadas de Cartagena de Indias", Historia y Cultura, 2, Cartagena, 1994, pp. 177-192.

Marixa Lasso: Mythis of harmony. Race and republicanism during the Age of Revolution, Colombia 1795-1831, Pittsburgh, University of Pittsburgh Press, 2007.

Ambrosio López: El desengaño, Bogotá, Incunables, 1985.

Flavia Macías: "Ciudadanía armada, identidad nacional y Estado provincial. Tucumán, 1854-1870”, en Hilda Sábato y Alberto Lettieri (comp.): La vida política en la Argentina del siglo XIX. Armas, votos y voces, México, Fondo de Cultura Económica, 2003, pp. 137-156.

Juan Marchena: "Sin temor de Rey ni de Dios. Violencia, corrupción y crisis de autoridad en la Cartagena colonial", en Alla Kuethe y Juan Marchena (eds.): Soldados del Rey. El ejército borbónico en América colonial en vísperas de la Independencia, Valencia, Universitat Jaume I, 2005, pp. 31-100.

Alberto Mayor: Cabezas duras y dedos inteligentes, Bogotá, Colcultura, 1997.

Alfonso Múnera: El Fracaso de la nación, Bogotá, Banco de la República-El Áncora eds., 1997.

José Murilo: "Dimensiones de la ciudadanía en el Brasil del siglo XIX", en Hilda Sábato (coord.): Ciudadanía política y formación de las naciones, 1999, pp. 321-344. 
Francisco Núñez: "El concepto de vecino/ciudadano en Perú, 1750-1850”, Araucaria, 9-17, Sevilla, 2007, pp. 235-253.

Marcos Palacio y Frank Safford: Colombia, País fragmentado, sociedad dividida, Bogotá, Norma, 2002.

Víctor Peralta: "El mito del ciudadano armado", en Hilda Sábato (coord.): Ciudadanía política y formación de las naciones, 1999, pp. 231-252.

Tomás Pérez: "Privilegios, organizaciones gremiales y academias de bellas artes: el caso de Nueva España”, en Beatriz Rojas (coord.): Cuerpo político y pluralidad de derechos. Los privilegios de las corporaciones en Nueva España, México, CIDE-Instituto Mora, 2007, pp. 189-214.

Sonia Pérez Toledo: "El ejército en la Ciudad de México a mediados del siglo XIX: datos y reflexiones acerca de su composición social", en Jaime Rodríguez (coord.): Las nuevas naciones. España y México 1800-1850, Madrid, Mapfre, 2008, pp. 315-336.

Manuel Pombo y José Guerra (comps.): Constituciones de Colombia, Bogotá, Biblioteca de Cultura Económica, 1951.

Eduardo Posada: "Alternancia y República: elecciones en la Nueva Granada y Venezuela, 1835-1837”, en Hilda Sábato (coord.): Ciudadanía política y formación de las naciones. Perspectivas históricas de América Latina, 1999, pp. 162-180.

— "Malabarismos electorales: Una historia comparativa de la corrupción del sufragio en América Latina, 1830-1930", en El desafío de las ideas. Ensayos de historia intelectual y política en Colombia, Medellín, Universidad Eafit, 2003, pp. 70-90.

Joaquín Posada Gutiérrez: Memorias histórico-políticas, tomo II, Bogotá, Biblioteca de Historia Nacional, 1929.

Luís Prado: "Ejército republicano y contrato social en las Provincias del Cauca, 1830-1850”, en César Torres y Saúl Rodríguez (eds.): De milicias reales a militares contrainsurgentes: La institución militar en Colombia del siglo XVIII al XXI, Bogotá, Universidad Javeriana, 2008, pp. 169-201. p. 230.

Steinar Saether: "La Independencia y la redefinición del concepto de Indianidad alrededor de Santa Marta, Colombia, 1750-1850", en Memorias, 9, Barranquilla, 2008.

James Sanders: Contentious Republicans. Popular politics, Race, and Class in Nineteenth-century Colombia, Durham, Duke University Press, 2004.

William Sewell Jr.: Trabajo y revolución en Francia. El lenguaje del movimiento obrero desde el Antiguo Régimen hasta 1848, Madrid, Taurus, 1992.

Sergio Paolo Solano: "Modelos bipolares, estilos de vida y capas medias en la historiografía social colombiana sobre el siglo XIX", Clío América, 3-6, Santa Marta, 2010a, pp. 193-213.

- "Trabajo, raza, artesanos y estilos de vida en Colombia, 1775-1875", en Sonia Pérez (coord.): Trabajo, trabajadores y movimientos sociales en 
México y América Latina, siglos XVIII y XIX, México, Universidad Autónoma Metropolitana, 2010b. (En prensa).

Sergio Paolo Solano y Roicer Flórez: "Imprentas, tipógrafos y estilos de vida en el Caribe colombiano, 1850-1930”, Palobra, 9, Cartagena, 2008, pp. 125-144.

Sergio Paolo Solano, Roicer Flórez y William Malkún: “Ordenamiento territorial y conflictos jurisdiccionales en el Bolívar Grande, 1800-1886”, Historia Caribe, 13, Barranquilla, 2008, pp. 65-119.

David Sowell: Artesanos y política en Bogotá, 1832-1919, Bogotá, Pensamiento Crítico-Círculo de Lectura Alternativa, 2006.

Vanesa Teitelbaum: Entre el control y la movilización. Honor, trabajo y solidaridades artesanales en la ciudad de México a mediados del siglo XIX, México, El Colegio de México, 2008.

Clement Thibaud: Repúblicas en Armas: los ejércitos bolivarianos en la guerra de independencia en Colombia y Venezuela, Bogotá, Planeta, 2003.

María Teresa Uribe: "El republicanismo patriótico y el ciudadano armado", en Estudios Políticos, 24, Medellín, 2004, pp. 75-92. 